\title{
A Method for Current Control of the Flywheel Energy Storage System Used in Satellites
}

\author{
Reşat ÇELIKEL, Mehmet ÖZDEMIR
}

\begin{abstract}
Satellites have a dark region and a bright region in their orbit path. The flywheel energy storage unit is an electric energy provider for a satellite in the dark region. Brushless dc motors (BLDC) are used in the flywheel energy storage unit. The current surge of the BLDC motors is an undesirable situation for solar panels which are used in the satellite motion systems and satellite power systems. Therefore, the current reference method (CRM) is preferred in these systems. The setting of the controller parameters (proportional $(P)$, integral $(I)$ and derivative $(D))$ is an important problem for the control of the BLDC motor current. Optimum performance cannot be obtained by the calculation of PID parameters using conventional methods. In recent years, hybrid genetic algorithms (GA) are used in the solution of complex problems. In this study, a CRM method was proposed to protect the satellite power system and solar panels. The defined block diagram for the CRM method was used to control the current of the BLDC. In order to calculate conventional method and hybrid GA-based method, the performance of the PID controllers was compared by using MATLAB/SimPowerSystem blocks.
\end{abstract}

Keywords: brushless dc motors; current reference method; energy storage; flywheel; genetic algorithms

\section{INTRODUCTION}

The flywheel energy storage system is used in many industrial applications such as wind farm, moment control gyroscope, transport/hybrid vehicles, compressor, and Uninterruptible Power Supply (UPS) [1-4]. The satellites complete the orbit consisting of bright and dark regions in ninety minutes. Completion of the bright region and dark region takes sixty and thirty minutes, respectively. When the satellites operate in the dark region, the required energy is provided by the chemical batteries or the mechanical energy storage units. The high-speed flywheel energy storage system (HSFESS) stores the mechanic energy in the region where the sun exists. This energy is used by the satellite in the region where the sun does not exist. Therefore, the energy of a satellite is provided by the solar panels in bright region $[5,6]$.

In recent years, the BLDC motors are extensively preferred in mechanic energy storage systems in addition to the automotive technology, medical devices and industrial applications. The high-speed BLDC motors have important features such as high efficiency, high reliability, low weight, and simple switching technique. The highspeed BLDC motors are generally preferred in the HSFESS which is used to store energy [7-9]. The BLDC motors are preferred due to the simple switching technique and their capability in the satellite motion system. The commutation point of the high-speed BLDC is important because of the low inductance causing current spike. Therefore, the performance of the high-speed BLDC motors has been increased by using a novel sensorless drive method [10]. In the satellite power section, the current fluctuation of the BLDC motor is an important problem when mechanic problems occur while it operates in the charge mode. The cost of the solar panels increases due to these current surges [11]. Therefore, the CRM is preferred in order to reduce the cost and size of the solar panels. It provides indirect speed control without using the speed controller. The current surges in BLDC motor are restrained by this method when disruptive impact occurs in the system.

The current spikes occur due to the low inductance of the high speed BLDC. The passive filter is used to decrease current spikes. The motor current is controlled by PID controller. The PID controllers are usually chosen because of their simple structure, easy design and cheap cost. Setting the PID controller parameters is very important for optimal controller performance [12]. The transfer function is used to control the BLDC motor current. The transfer function of the HSFESS consists of inverter, filter, and BLDC motor and current sensor. The optimization of the PID controller parameters is realized by using the system transfer function of the HSFESS. Thus, the system is simplified and PID controller parameters are easily set according to the conventional method. Genetic algorithms are a type of the stochastic algorithm based on principles of the natural selection and genetics. The genetic algorithms are usually used to obtain optimum results from complex problems. Many problems have been solved with the aid of the genetic algorithms in a variety of workspaces. Therefore, genetic algorithms have increased their popularity in recent years [13]. Genetic Algorithms are used to solve complex problems and optimization problems such as estimation of losses in radial distribution networks and unknown convection coefficients in the lumped-parameter thermal network $[14,15]$.

It has been shown that genetic algorithms are capable to locate high-performance areas in complex domains without experiencing the difficulties associated with high dimensionality or false optima as may occur with normal PID techniques [16]. In Ref. [17], the PI controller parameters of a DC-DC single-ended primary inductance converter was tuned by using GA. Genetic algorithm has always obtained optimum result in the control variables which are controllers of speed, torque, and current. Nowadays, the traditional GA, as well as hybrid GA, is used in the solution of problems. The hybrid GA solves problems by using direct search methods. The hybrid GA method was formed by combining a pattern search algorithm and a genetic algorithm.

In this paper, a CRM was proposed to protect the solar power system of satellites. The current reference was generated by calculating the system losses. A LC-trap filter was designed to decrease current ripples of BLDC motor. The transfer function of the HSFESS was obtained to control the current of the high-speed BLDC. The parameters of the PID controller were calculated by using 
hybrid GA which was used to obtain optimum performance. On the other hand, the parameters of the PID controller were calculated by a conventional method (Ziegler-Nichols method). The proposed and conventional methods were compared by using MATLAB/ SimPowerSystem blocks. The current spikes were decreased by using the proposed method in the steady state. The CRM eliminated the current fluctuations when mechanical problems, such as mechanical resonances, occurred.

\section{HIGH SPEED FLYWHEEL ENERGY STORAGE SYSTEM}

The BLDC motor is produced as three-phase winding in the stator and permanent magnet rotor. The hall-effect sensors determine the rotor position at each $60^{\circ}$. The sensor information is used to realize the electronic commutation in the motor drive. The BLDC motor is controlled by using the six-step drive method whose position information is obtained by hall-effect sensors. Fig. 1 shows parts of the HSFESS consisting of BLDC motor, inverter, sensors, flywheel, and LC filter. The modelling of the BLDC motor is based on these assumptions: The saturation of motor and iron losses is neglected. The stator resistances of all windings are equal and self/mutual inductances are constant and the power semiconductor devices are ideal in the inverter. A BLDC motor with a six-step drive is similar to a direct current motor. The mathematical expression of the direct current motor is presented from Eq. (1) to (5).

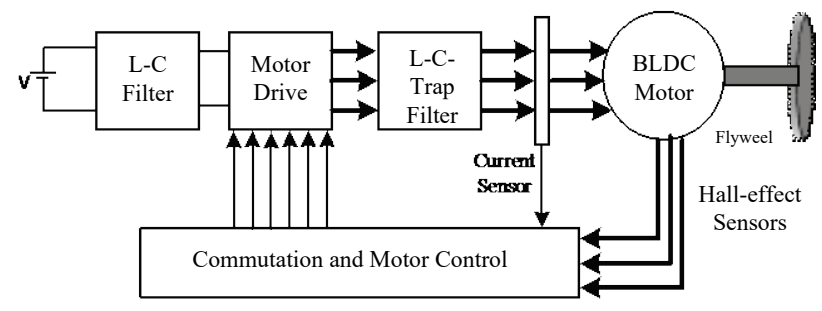

Figure 1 The HSFESS system

$\left[\begin{array}{l}V_{\mathrm{a}} \\ V_{\mathrm{b}} \\ V_{\mathrm{c}}\end{array}\right]=\left[\begin{array}{ccc}R & 0 & 0 \\ 0 & R & 0 \\ 0 & 0 & R\end{array}\right]\left[\begin{array}{c}I_{\mathrm{a}} \\ I_{\mathrm{b}} \\ I_{\mathrm{c}}\end{array}\right]+\left[\begin{array}{ccc}L & 0 & 0 \\ 0 & L & 0 \\ 0 & 0 & L\end{array}\right] \frac{\mathrm{d} t}{\mathrm{~d} t}\left[\begin{array}{c}I_{\mathrm{a}} \\ I_{\mathrm{b}} \\ I_{\mathrm{c}}\end{array}\right]+\left[\begin{array}{c}e_{\mathrm{a}} \\ e_{\mathrm{b}} \\ e_{\mathrm{c}}\end{array}\right]$

where $R$ is the phase resistance, $L$ is the phase inductance, $e_{\mathrm{a}}, e_{\mathrm{b}}$, and $e_{\mathrm{c}}$ are the phase back EMFs, $I_{\mathrm{a}}, I_{\mathrm{b}}$ and $I_{\mathrm{c}}$ are the phase currents of the BLDC motor. The six-step driving method is preferred to control the BLDC motor in highspeed applications. The reference current used in the proposed motor drive algorithm is obtained by using Eq. (6) and (7). The transfer function ensuring the control of the motor current is obtained by using Eq. (8) and Eq. (9). This transfer function has been used to control BLDC motor current as shown in Eq. (10). The expressions given in Eq. (1) and Eq. (2) belong to the inverter and the sensor, which are parts of the HSFESS, respectively.

$V=i_{\mathrm{a}} R_{\mathrm{a}}+L_{\mathrm{a}} \frac{\mathrm{d} i_{\mathrm{a}}}{\mathrm{d} t}+E_{\mathrm{z}}$

$E_{\mathrm{z}}=K_{\mathrm{e}} \omega_{\mathrm{m}}$
$T_{\mathrm{m}}=T_{\mathrm{L}}+J \frac{\mathrm{d} \omega_{\mathrm{m}}}{\mathrm{d} t}+B \omega$

$T_{\mathrm{m}}=K_{\mathrm{t}} i_{\mathrm{a}}$

$T_{\text {mech }} \omega_{\mathrm{m}}=i_{\mathrm{a}} E_{\mathrm{z}}=P_{\text {mech }}$

$i_{\text {ref }}=\frac{P_{\mathrm{acc}}+P_{\mathrm{fr}}+P_{\mathrm{wind}}}{E_{\mathrm{z}}}$

$V(s)=i_{\mathrm{a}}(s) R_{\mathrm{a}}+s L_{\mathrm{a}} i_{\mathrm{a}}(s)+K_{\mathrm{e}} \omega_{\mathrm{m}}(s)$

$K_{\mathrm{t}} i_{\mathrm{a}}(s)=T_{\mathrm{L}}+J s \omega_{\mathrm{m}}(s)+B \omega_{\mathrm{m}}(s)$

$\frac{i_{\mathrm{a}}(s)}{V(s)}=\frac{J s+B}{L_{\mathrm{a}} J s^{2}+\left(R_{\mathrm{a}} J+L_{\mathrm{a}} B\right) s+R_{\mathrm{a}} B+K_{\mathrm{e}} K_{\mathrm{t}}}$

$T_{\mathrm{c}}(s)=\frac{K_{\mathrm{c}}}{T_{\mathrm{c}} s+1}$

$T_{\mathrm{a}}(s)=\frac{K_{\mathrm{a}}}{T_{\mathrm{a}} s+1}$

where $V$ is the motor voltage, $i_{\mathrm{a}}$ is the motor current, $R_{\mathrm{a}}$ is the resistance of the motor winding, $L_{\mathrm{a}}$ is the inductance of the motor winding. $T_{\mathrm{c}}$ is time constant of inverter, $K_{\mathrm{c}}$ is the gain of inverter, $T_{\mathrm{a}}$ is the time constant of current sensor, $K_{\mathrm{a}}$ is the gain of current sensor, $E_{z}$ is the back EMF, $K_{\mathrm{e}}$ is the motor speed constant, $K_{\mathrm{t}}$ is the torque constant of the motor. $T_{\mathrm{m}}$ is the torque generated by the motor, $T_{\text {mech }}$ is the mechanic torque generated by the motor, $\omega_{\mathrm{m}}$ is the speed of the motor, $J$ is the total inertia moment of the flywheel and the motor, and $B$ is the friction coefficient. $P_{\text {mech }}$ is the mechanic power of the motor, $P_{\text {acc }}$ is the speed-up power of the flywheel, $P_{\mathrm{fr}}$ is the total friction power in the system, $P_{\text {wind }}$ is the winding power of the system. The current reference must be generated by using the system losses occurring due to the total friction of the system. The losses due to the air friction are calculated as shown from Eq. (13) to (16). The environment must be vacuumed to decrease the air friction. Therefore, vacuum chamber is used to place the flywheel. The flywheel structure used in the system is depicted in the following figure.

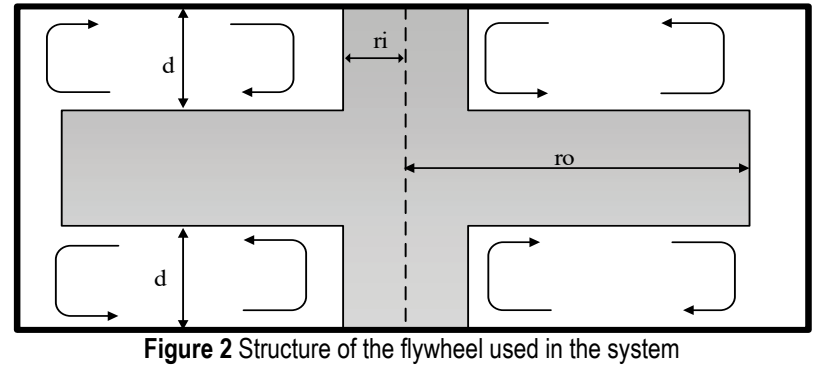

$P_{\text {wind }}=k_{\mathrm{f}} \times M_{\text {disc }} \times \omega_{\mathrm{m}}$

$C_{\mathrm{f}}=\frac{3.7 \times\left(\frac{d}{r_{\mathrm{o}}}\right)^{0.1}}{\sqrt{R_{\mathrm{e}}}}$

$M_{\text {disc }}=\frac{\left[\left(C_{\mathrm{f}} \times \rho_{\mathrm{a}} \times \omega_{\mathrm{m}}^{2}\right)\left(r_{\mathrm{o}}^{5}-r_{\mathrm{i}}^{5}\right)\right]}{2}$

$R_{\mathrm{e}}=\frac{\rho_{\mathrm{a}} \times \omega_{\mathrm{m}}^{2} \times r_{\mathrm{o}}^{2}}{\mu}$ 
where $k_{\mathrm{f}}$ is the smoothness factor, $R_{\mathrm{e}}$ is the Reynold's number, $\rho_{\mathrm{a}}$ is the density of the air, $r_{\mathrm{i}}$ is the inner radius of the flywheel, $r_{\mathrm{o}}$ is the outer radius of the flywheel, and $\mu$ is the viscos friction of the air. In HSFEES applications, the high-speed hybrid bearing is used due to the low viscosity of bearing grease oil. Calculation of the bearing friction losses is given from Eq. (17) to (22). The acceleration power of the flywheel is given in Eq. (23).

$P_{\mathrm{fr}}=\left(M_{0}+M_{1}\right) \omega_{\mathrm{m}}$

$M_{0}=f_{0} \times(v \times n)^{\frac{2}{3}} \times d_{\mathrm{m}}^{3} \times 10^{-10}$

$M_{1}=f_{1} \times P_{1} \times d_{\mathrm{m}}$

$P_{1}=\omega_{\mathrm{m}}\left(F_{\mathrm{r}}+F_{\mathrm{b}}\right)$

$F_{\mathrm{r}}=m \times g$

$F_{\mathrm{b}}=m_{\mathrm{r}} \times e \times \omega_{\mathrm{m}}^{2}$

$P_{\mathrm{acc}}=J \times \omega_{\mathrm{m}} \times \frac{\Delta \omega_{\mathrm{m}}}{\Delta t}$

where $f_{0}$ and $f_{1}$ are the bearing constants (these constants are determined by the manufacturer), $n$ is the speed of the bearing, $v$ is the kinematic-viscos friction of the bearing grease, $m$ is mass of the flywheel, $m_{\mathrm{r}}$ is the residual mass of the flywheel, $e$ is the eccentricity between the gravity center and axis of rotation of the flywheel, and $d_{\mathrm{m}}$ is the mean value of the bearing diameter. $\Delta \omega_{\mathrm{m}}$ is the difference between minimum speed and maximum speed and $\Delta t$ is the acceleration time. $\Delta \omega_{\mathrm{m}}$ and $\Delta t$ are determined when the FESS is designed. Therefore, the $P_{\text {acc }}$ is determined as a constant.

\section{DESIGN OF FILTER AND PID}

The high current ripples occur because the high-speed BLDC motors have low inductance. In addition, these motors have high fundamental frequency $(500 \mathrm{~Hz}-1 \mathrm{kHz})$. Therefore, high switching frequency must be used in motor drive. On the other hand, stresses caused by voltage change appear on windings of the motor when the high on/off frequency is applied to the inverter of the motor drive. The passive filters connected to BLDC motor windings as series are used to decrease $\mathrm{dv} / \mathrm{dt}$ stress $[18,19]$.

The switching frequency harmonics are reduced by the trap filter. The filter designed for one-phase is shown in Fig. 3. The L-C-Trap filter is calculated to examine performance of the filter as shown in Eq. (24) and bode diagram of it is shown in Fig.4.

$$
\begin{aligned}
& \frac{V_{\mathrm{o}}(s)}{V_{\mathrm{i}}(s)}=\frac{a s^{4}+b s^{3}+c s^{2}+d s}{e s^{5}+f s^{4}+g s^{3}+h s^{2}+d s} \\
& a=L_{1} R_{1} C_{1} C_{2}^{2} \\
& b=L_{1} R_{2} C_{1} C_{2}^{2}+L_{1} R_{1} C_{1} C_{2}^{2} \\
& c=R_{1} R_{2} C_{1} C_{2}^{2}+L_{1} R_{1} C_{1} C_{2}^{2} \\
& d=C_{2}^{2} \\
& e=L_{1} L_{2} C_{1} C_{2}^{2}
\end{aligned}
$$

$$
\begin{aligned}
& f=L_{1} R_{2} C_{1} C_{2}^{2}+L_{1} R_{1} C_{1} C_{2}^{2} \\
& g=R_{1} R_{2} C_{1} C_{2}^{2}+L_{2} R_{1} C_{1} C_{2}^{2}+L_{1} C_{1} C_{2}+L_{1} C_{2}^{2}+L_{2} C_{2}^{2} \\
& h=R_{2} C_{2}^{2}+R_{1} C_{1} C_{2}
\end{aligned}
$$

where $L_{1}$ is the inductance of the trap filter, $R_{1}$ is the resistance of the trap filter, $C_{1}$ is the capacitance of the trap filter, $R_{2}$ is the resistance of the L-C filter, $C_{2}$ is the capacitance of the L-C filter, and $L_{2}$ is the inductance of the $\mathrm{L}-\mathrm{C}$ filter. The parameters of the L-C-Trap filter and other components of the HSFESS are shown as follows: $R_{1}=1.5$ $\Omega ; L_{1}=100 \mu \mathrm{H} ; C_{1}=100 \mathrm{nF} ; L_{2}=100 \mu \mathrm{H} ; R_{2}=1.8 \Omega ; C_{2}$ $=1 \mu \mathrm{F} ; K_{\mathrm{c}}=3.6 \mathrm{~V} / \mathrm{V} ; T_{\mathrm{c}}=T_{\mathrm{a}}=20 \times 10^{-6} \mathrm{~s} ; K_{\mathrm{a}}=1 \mathrm{~V} / \mathrm{A}$.

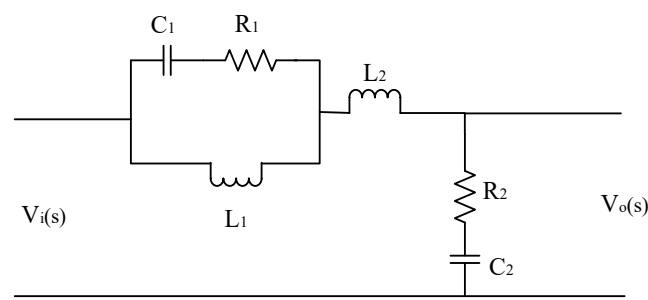

Figure 3 L-C-trap filter for one-phase winding of BLDC motor

Thus, the LC filter is used in order to decrease the current ripple and THD in the system. The corner frequency is obtained as shown in Eq. (25) and it is calculated as $15.93 \mathrm{kHz}$ for L-C filter. The resonance frequency of the trap filter is equal at switching frequency.

$f_{\mathrm{c}}=\frac{1}{2 \pi \sqrt{L_{(1,2)} C_{(1,2)}}}$

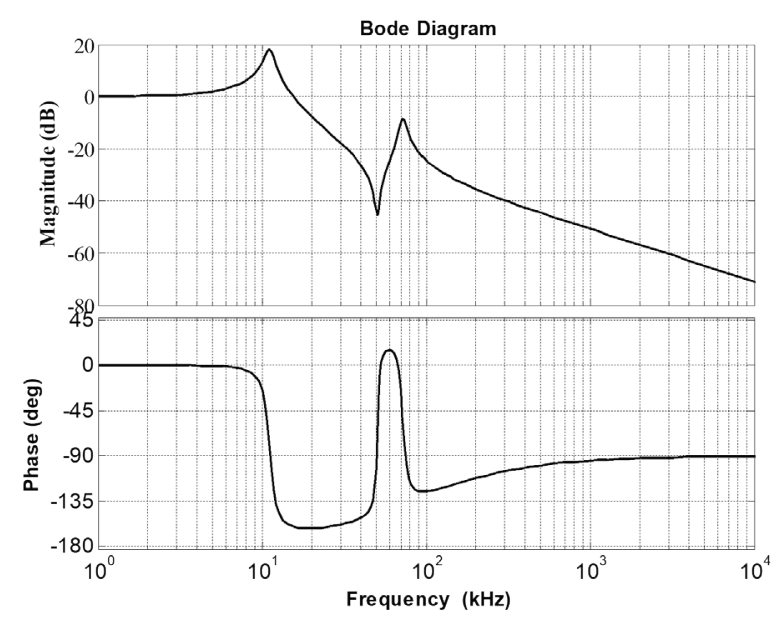

Figure 4 Bode diagram of the LC-trap filter

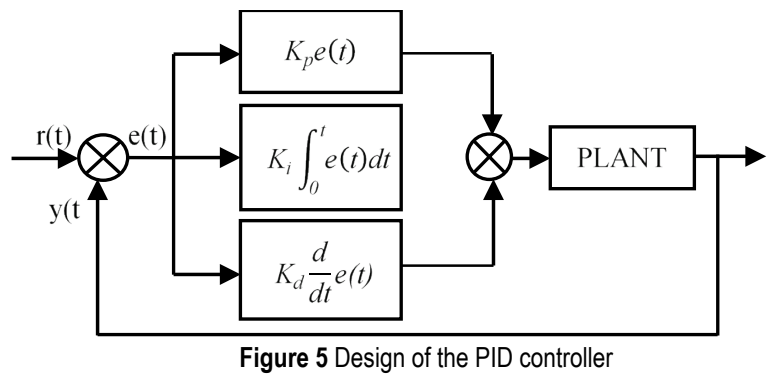

The PID controller is used in almost all industrial applications due to its simple structure and robust 
performance. The PID is used to minimize the steady-state error and to obtain high performance from the transient response of the system. The PID controller is shown in Fig. 5. The transfer functions given in Eq. (26) and (27) are required to calculate the PID controller parameters. The block schema of HSFESS consisting of controller, filter, inverter, BLDC motor, and sensor is seen in Fig.6. System parameters are given in $[20,21]$.

$$
\begin{aligned}
& U(t)=K_{\mathrm{p}} e(t)+K_{\mathrm{i}} \int_{0}^{t} e(t)+K_{\mathrm{d}} \frac{\mathrm{d}}{\mathrm{d} t} e(t) \\
& P I D(s)=\frac{s^{2} K_{\mathrm{d}}+s K_{\mathrm{p}}+K_{\mathrm{i}}}{s}
\end{aligned}
$$

\subsection{Ziegler-Nichols Method and GA/PS Optimization}

The Ziegler-Nichols method is used for the calculation of the PID parameter. In the closed-loop Ziegler-Nichols method, $K_{\mathrm{p}}$ is set while the system is at the point of oscillation $[22,23]$. While system oscillation point and $K_{\mathrm{p}}$, $K_{\mathrm{i}}, K_{\mathrm{d}}$ are computed as in Tab. 1, ultimate gain $K_{\mathrm{u}}$ and ultimate period $T_{\mathrm{u}}$ are obtained.

GAs are an optimization technique which is used to solve the complex problems and based on natural selection. GAs solve problems by using three important operators that are obtained through selection, crossover and mutation. GA firstly creates an initial population in the study area. Afterward, it improves individual solutions of the initial population. The best individual solution of the population is obtained by using the selection operator. When the most appropriate individual solution of the population defined within the limits of fitness function is not created, the crossover operator creates new individuals and these new individuals form mixing couples selected from individuals in the population. The mutation operator creates a new individual which is selected randomly in a chromosome. These operations are repeated until the most appropriate value of the fitness function is found inside the limits of the fitness function. In addition, the control parameters determining the limits of GA consist of population size and type, fitness limit, and functions of selection, crossover, and mutation rate [24, 25].

Table 1 Tuning the PID with the Ziegler-Nichols method

\begin{tabular}{|c|c|c|c|}
\hline \multicolumn{4}{|c|}{ Ziegler-Nichols Method } \\
\hline Control Type & $K_{\mathrm{p}}$ & $K_{\mathrm{i}}$ & $K_{\mathrm{d}}$ \\
\hline $\mathrm{P}$ & $0,5 K_{\mathrm{u}}$ & - & - \\
\hline PI & $0,45 K_{\mathrm{u}}$ & $1,2 K_{\mathrm{p}} / T_{\mathrm{u}}$ & - \\
\hline PID & $0,6 K_{\mathrm{u}}$ & $2 K_{\mathrm{p}} / T_{\mathrm{u}}$ & $K_{\mathrm{p}} T_{\mathrm{u}} / 8$ \\
\hline
\end{tabular}

One of the direct search algorithms is the pattern search algorithm, in which the minimum of a continuous function is sought without using the derivatives of the function. The Pattern Search (PS) optimization routine is an evolutionary technique that is suitable to solve a variety of optimization problems that are out of the scope of the standard optimization methods. Generally, the PS algorithm has the advantages of being very simple in concept, easy to implement and computationally efficient.

In references [26] and [27], a historical research of the direct search methods is presented for unconstrained optimization. The complex problem, which is used to minimize the value of the fitness function, can be solved by using the hybrid optimization algorithm. In this respect, the hybrid optimization function is important in terms of solving complex problems. The optimization of the PID parameters has been performed by using hybrid GA/PS. Firstly, GA has been operated to obtain the value of the fitness function which creates the initial value of the PS algorithm. Thus, the solution area of the PS algorithm has been defined in order to decrease the solution time and error. Also, because the initial value of the solution area has been determined by using the PS algorithm, some of the local minimum and maximum values have been eliminated. The hybrid GAs aim to minimize the value of the fitness function which is created with the error criteria. The amount of error is obtained by using the step response of the transfer function seen in Fig. 6. The fitness function is created with the error criteria obtained by using the error amount. Some definitions of GA are given in Tab. 2.

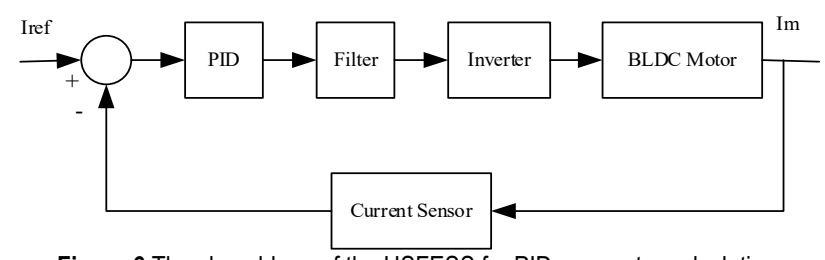

Figure 6 The closed-loop of the HSFESS for PID parameter calculation

\begin{tabular}{|c|c|}
\hline Upper Bound & {$\left[\begin{array}{llll}5 & 1000 & 1000\end{array}\right]$} \\
\hline Lower Bound & {$\left[\begin{array}{lll}0 & 0 & 0\end{array}\right]$} \\
\hline Population Size & 100 \\
\hline Population Type & Double Vector \\
\hline Generations & 50 \\
\hline Fitness Limit & $1 \mathrm{e}-5$ \\
\hline Fitness Scaling Function & Rank \\
\hline Selection Function & Stochastic Uniform \\
\hline Hybrid Function & Pattern Search \\
\hline Crossover Function & Scattered \\
\hline
\end{tabular}

Table 2 Some definitions of GA

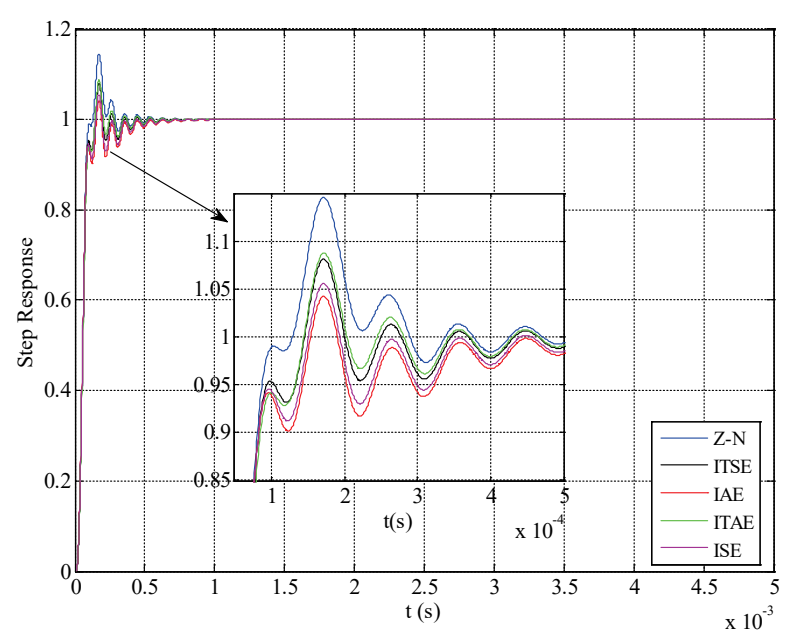

Figure 7 The unit step response of the system using Z-N and the proposed method

In reference [28], some error criteria used in the calculation of the optimum values of the PID parameters are given. For a PID-controlled system, there are often four indices depicting the system performance: IAE, ISE, ITAE and ITSE. These error criteria are given from Eq. (28) to (31). They have been applied to the system which is shown in Fig. 6. 


$$
\begin{aligned}
& I A E=\int_{0}^{\tau}|e(t)| \mathrm{d} t \\
& I S E=\int_{0}^{\tau} e(t)^{2} \\
& I T A E=\int_{0}^{\tau} t|e(t)| \mathrm{d} t \\
& I T S E=\int_{0}^{\tau} t e(t)^{2} \mathrm{~d} t
\end{aligned}
$$

Unit step response of the system is shown in Fig. 7. The optimal result has been obtained by using integral absolute error criterion and the overshoot value has been determined as $4.2 \%$. According to step responses of the

\begin{tabular}{|c|c|c|c|c|c|c|c|}
\hline & Rise Time & Peak Time & Settling Time & Overshoot & $K_{\mathrm{p}}$ & $K_{\mathrm{i}}$ & $K_{\mathrm{d}}$ \\
\hline Z-N & $6.087 \times 10^{-5}$ & $1.71 \times 10^{-4}$ & $8.8 \times 10^{-4}$ & 14.5 & 0.099 & 990 & $2.4 \times 10^{-6}$ \\
\hline GA/PS-ITSE & $6.089 \times 10^{-5}$ & $1.72 \times 10^{-4}$ & $8.8 \times 10^{-4}$ & 8.1 & 0.102 & 837.544 & 0 \\
\hline GA/PS-IAE & $6.016 \times 10^{-5}$ & $1.72 \times 10^{-4}$ & $9 \times 10^{-4}$ & 4.2 & 0.105 & 748.296 & 0 \\
\hline GA/PS-ITAE & $6.168 \times 10^{-5}$ & $1.722 \times 10^{-4}$ & $9 \times 10^{-4}$ & 8.75 & 0.099 & 847 & 0 \\
\hline GA/PS-ISE & $6.065 \times 10^{-5}$ & $1.722 \times 10^{-4}$ & $9.2 \times 10^{-4}$ & 5.55 & 0.104 & 778.809 & 0 \\
\hline
\end{tabular}
system, the values of performance and $K_{\mathrm{p}}, K_{\mathrm{i}}, K_{\mathrm{d}}$ are given in Tab. 3 .

Table 3 Performance values of error criteria by GA/ps and Z-N method

\section{SIMULATION}

The load change occurs due to mechanical problems in the flywheel energy storage unit with BLDC motor. The sudden current changes occur because of the load change in the BLDC motor. These current changes must be eliminated in order to protect the power system of the satellite. The current of the motor must be limited in order to decrease the power demand. Thus, the size of solar panel is not increased when the current surge occurs. The effect of the load change is decreased by using the proposed current control method in the power system of the HSFEES. In this method, the desired flywheel speed is reached by the generated current reference. The current reference is calculated by using the system losses, the back EMF, and the acceleration power. The reference speed of the motor is calculated by using the losses of the HSFESS. The reference speed of the system is generated to reach the determined speed value and it continually increases within the determined time. When destructive effect occurs, the speed of the motor decreases since the direct speed control is not performed in the system.

When disruptive impacts such as mechanical resonance occur, the speed of the motor decreases. The speed of the system is captured in the desired time after the disruptive effect disappears. The motor-acceleration reference power is taken as zero when the speed of the system reaches the highest speed, which has been defined in the designed system, and the BLDC motor provides only the losses of the system. The flowchart of the algorithm used to generate the current reference is shown in Fig. 8. The current reference is increased according to increasing reference speed. The load torque of the high-speed BLDC motor is obtained by using system losses which are determined by the system speed. PI controller is used in the control of the motor current.

The waveform of the BLDC phase-current motor is obtained from the waveforms of the Hall-effect sensors. PWM waveforms are generated by comparison of the current waveforms with the carrier triangle wave. Because of the high speed of the HSFESS, the simple drive technique is required. In the applications, the six-step technique is used since it is the most simple drive technique for the driving of the BLDC motor. The simple control method is important at high-speed BLDC motor in terms of the processing capability of the microcontroller.

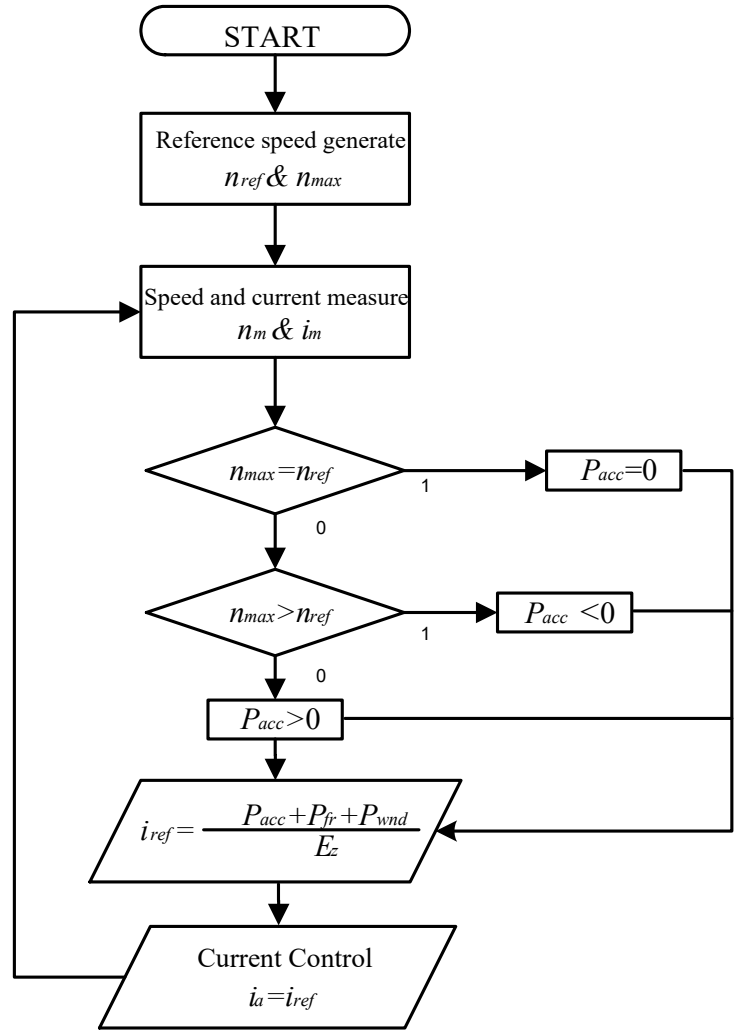

Figure 8 Algorithm to generate current reference

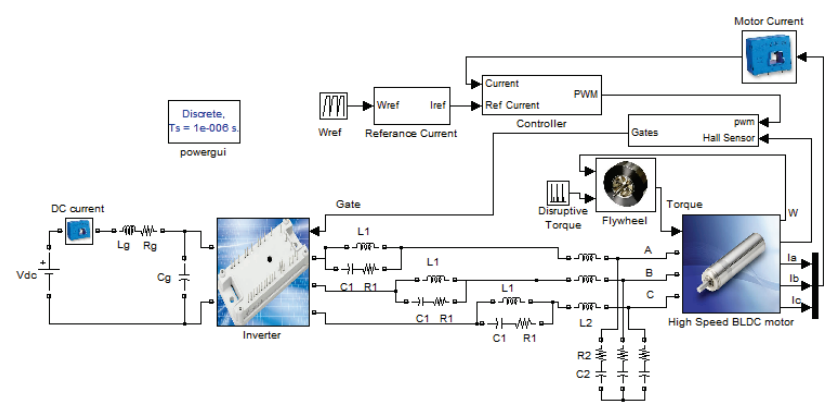

Figure 9 The MATLAB/PowerSystemBlock model of HSFESS

The CRM system which was simulated by using MATLAB/SimPowerSystem blocks is shown in Fig. 9. The sample time was taken as $1 \mu \mathrm{s}$ in the simulation. The sampling time of the current controller was taken as $20 \mu \mathrm{s}$. The switching frequency of inverter was $50 \mathrm{kHz}$ and MOSFET was used in three-phase inverter. The speed of the system reached from 0 to $4200 \mathrm{r} / \mathrm{s}$ within 32.5 minutes. 
The EC-25 BLDC motor which was manufactured by Maxon motor company was used in the simulation. The parameters of bearing, flywheel and environment are given as follows: $J=0.00425 \mathrm{kgm}^{2} ; \mu=1.935 \times 10^{-5} \mathrm{~kg} / \mathrm{ms} ; k_{\mathrm{f}}=$ $1 ; \rho_{\mathrm{a}}=0.001 \mathrm{~kg} / \mathrm{m}^{3}$ at $1 \mathrm{mbar}$ ambient pressure; $d_{\mathrm{m}}=18 \mathrm{~mm}$; $v=6 \mathrm{~mm}^{2} / \mathrm{s} ; f_{0}=1.3 ; f_{1}=0.0003 ; m=0.85 \mathrm{~kg} ; g=9.8 \mathrm{~m} / \mathrm{s}^{2}$; $m_{\mathrm{r}}^{*} e=11.67 \mathrm{~N} ; r_{\mathrm{o}}=0.1 \mathrm{~m} ; d=0.05 \mathrm{~m}$.

The change of the load torque was computed according to the reference speed of the system which is shown in Fig. 10(a). The disruptive impact occurred at $1005^{\text {th }} \mathrm{s}$. In the conventional method, the motor speed has tracked the reference speed when the disruptive effect occurred as depicted in Fig. 10(b). The speed of the flywheel has been changed between $0^{\text {th }} \mathrm{s}$ and $2050^{\text {th }} \mathrm{s}$.

The change of motor phase current and dc link current of the three-phase inverter has been shown between $0^{\text {th }} \mathrm{s}$

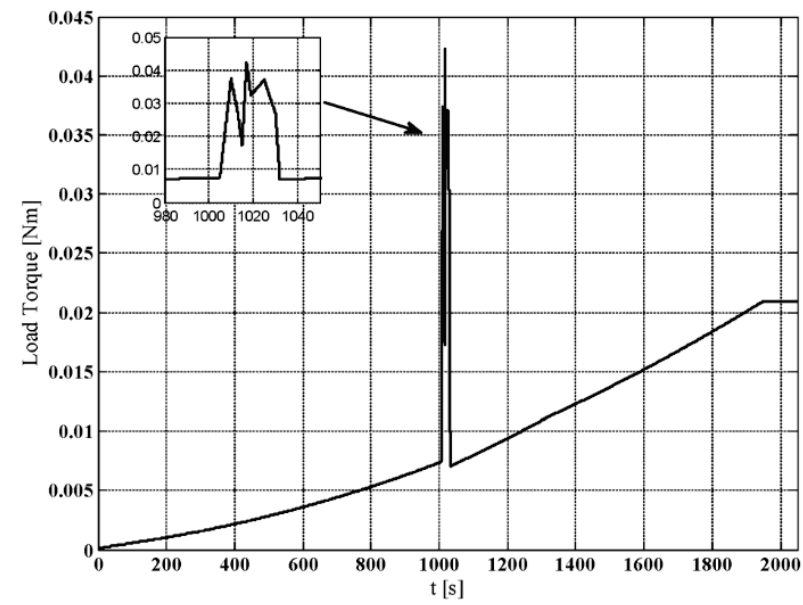

(a)

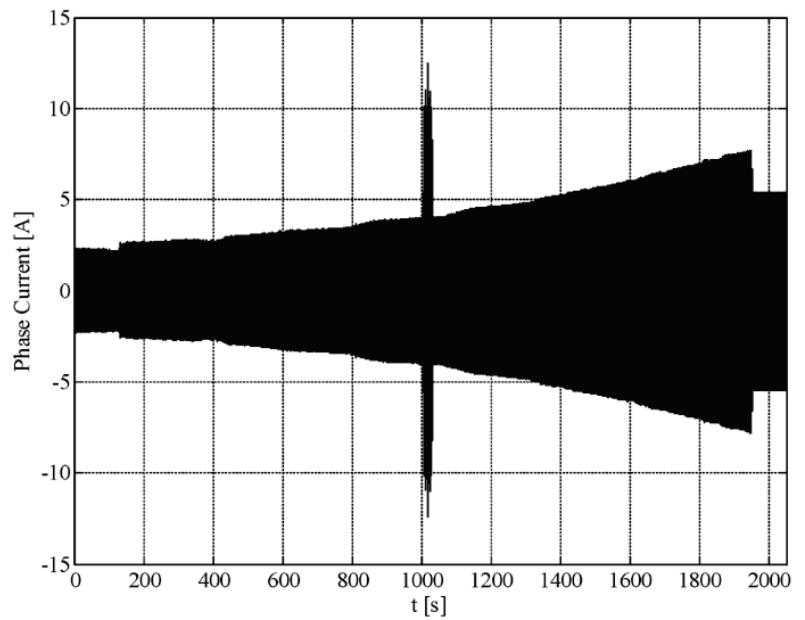

(c) and $2050^{\text {th }} \mathrm{s}$ in Fig. 10(c) and Fig. 10(d), respectively. The dc supply current and the BLDC motor current have been increased by PI controller when the disruptive impact (mechanical problems) has occurred in the HSFESS. The motor current is limited by the maximum current of BLDC motor.

If the mechanical resonance occurs in the system, the BLDC motor will require more current, but current limiting will not allow it. The current fluctuations are still high and at undesired levels, and the CRM method is recommended to prevent these current fluctuations. Speed and load torque of the high speed BLDC motor in the CRM when disruptive effect occurred at $1005^{\text {th }} \mathrm{s}$ have been demonstrated in Fig. 11. The single-phase current of the high-speed BLDC motor has been demonstrated in Fig. 12.

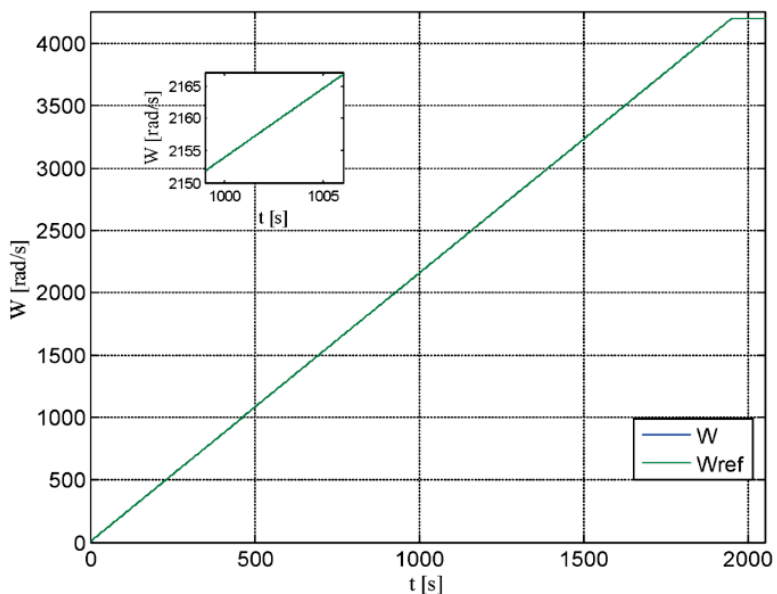

(b)

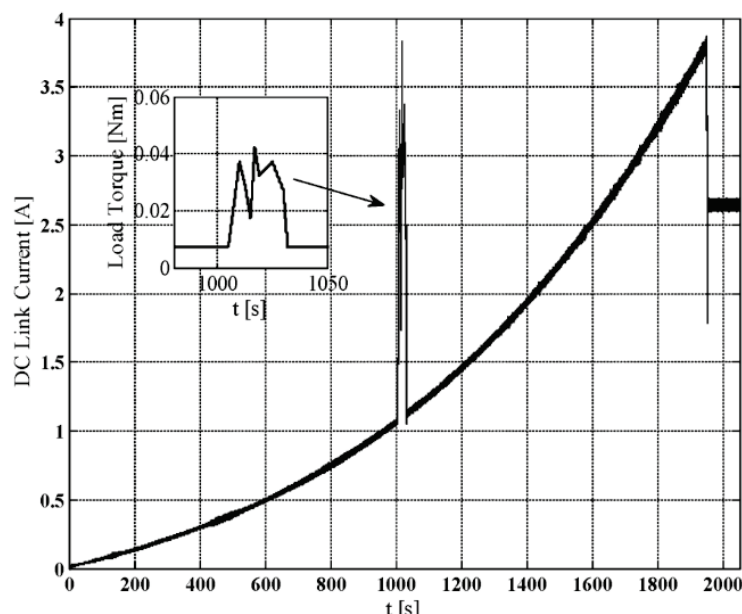

(d)

Figure 10 Conventional speed control: a) The load torque b) The BLDC motor speed c) A phase current of BLDC motor d) DC link current of inverter

The DC input current and the single-phase current of BLDC motor did not increase when disruptive effect occurred at $1005^{\text {th }} \mathrm{s}$. Thus, the motor current and the DC link current have been followed by the reference current. The speed has decreased since the load torque of BLDC motor has increased. The speed of the BLDC motor increased when disruptive effect disappeared, and after a while it reached the reference speed. The calculation methods of the conventional PID parameter and the proposed PID parameter have been compared as shown in Fig. 12 and Fig. 13. The current ripple of single-phase of the BLDC motor and the current ripple of the DC supply have been decreased by using the GA/PS-based CRM as shown in Fig. 12 and Fig. 13.

The current ripple of single-phase of the BLDC motor is about 20A without the LC-trap filter. The high current ripple has occurred due to the low motor inductance. Therefore, the LC filter has been used in the system to decrease the current ripple and the total harmonic distortion (THD). The THD and current ripples of the BLDC motor have been considerably declined as shown in Fig. 14. When the speed of the BLDC motor is at $4200 \mathrm{rad} / \mathrm{s}$, the effect of trap-LC filter has been demonstrated in Fig. 14(a), Fig. 14(b) and Fig. 14(c). The switching frequency 
harmonics have been reduced by using trap filter as shown in Fig. 14(c). The THD of motor phase-current has been performed by $141.64 \%$ as shown in Fig. 14(a), by $40.49 \%$ as shown in Fig. 14(b), and by $31.34 \%$ as shown in Fig. 14(c).

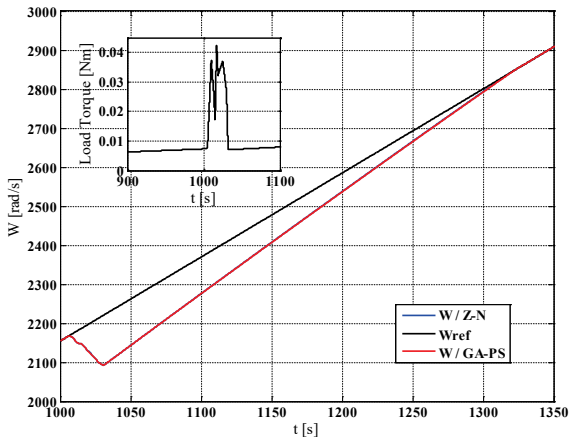

Figure 11 Speed of BLDC motor in CRM: Between 1000 and $1350 \mathrm{~s}$
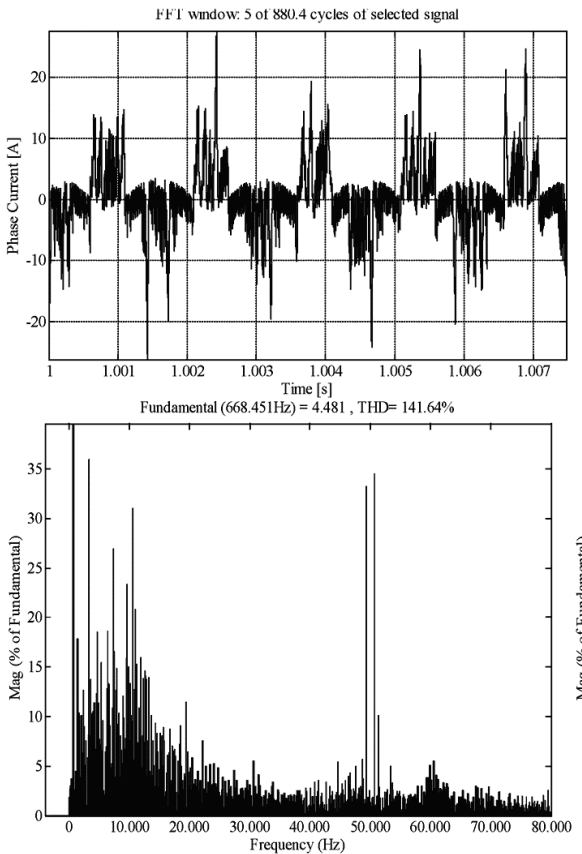

(a)

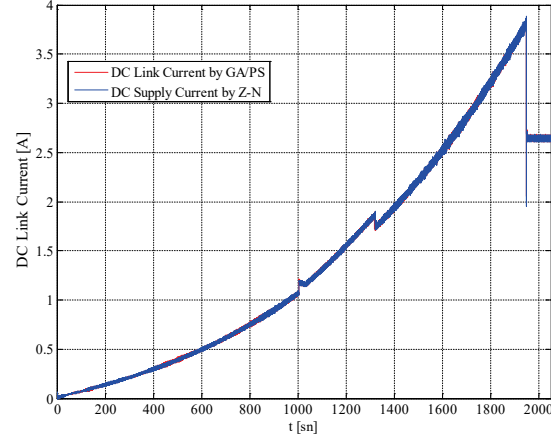

Figure 12 The single-phase current of BLDC motor by using proposed method
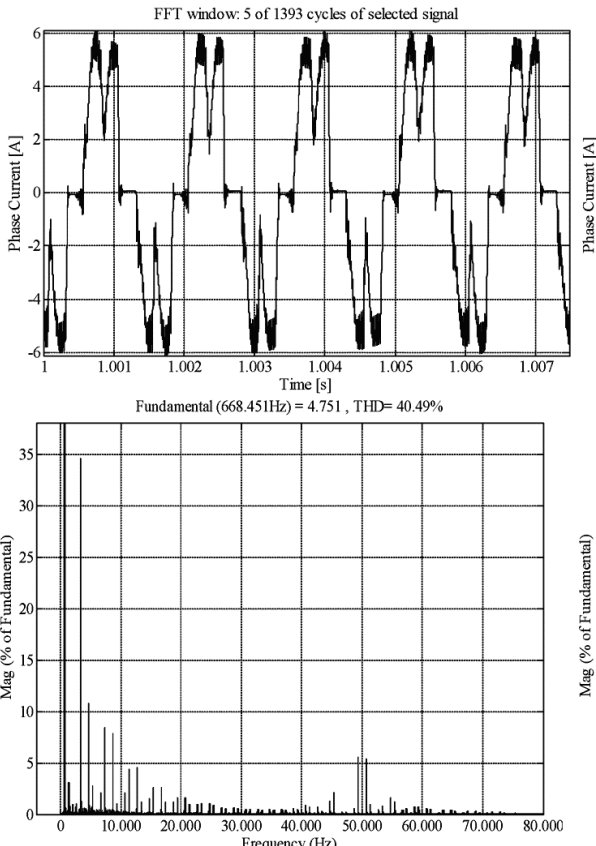

(b)

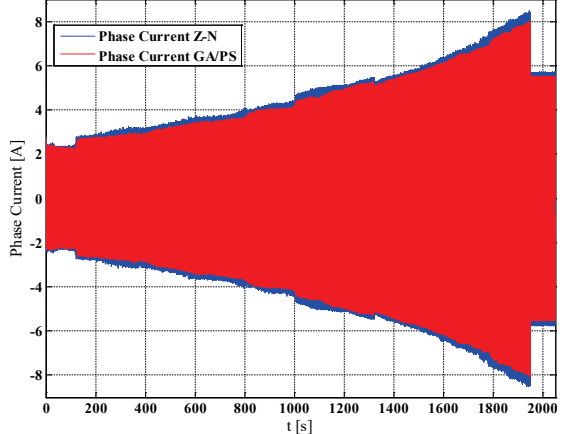

Figure $13 \mathrm{DC}$ link current in CRM: Between 0 and $2050 \mathrm{~s}$
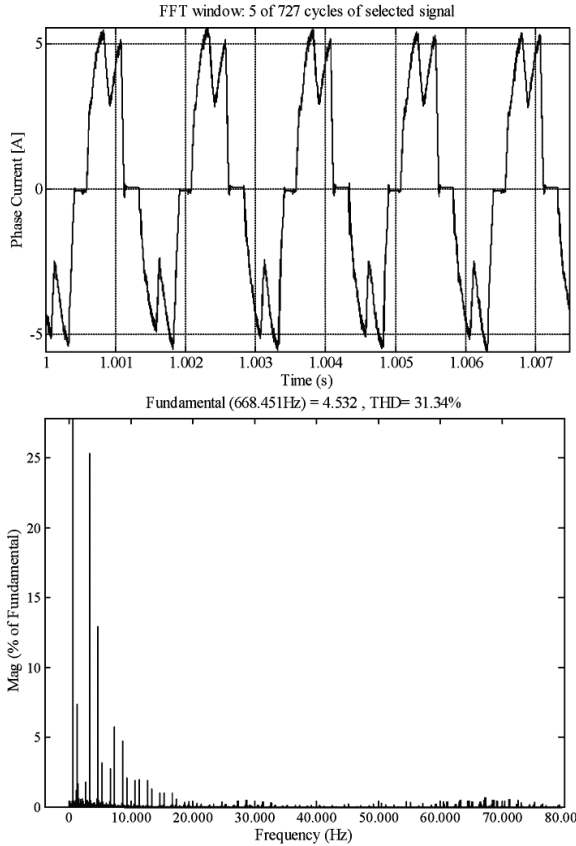

(c)

Figure 14 The phase current and harmonic spectrum of BLDC motor at 4200rad/s: a) without filter, b) By using LC filter, c) By using trap-LC filter

\section{CONCLUSION}

In this paper, the HSFESS and the CRM was presented for a satellite power system application. The simulation was performed by MATLAB/ SimPowerSystem blocks which consisted of current reference, high speed BLDC motor drive and flywheel torque. In addition, simulation of the HSFESS was performed for the conventional control method and proposed CRM. When the disruptive torque occurred, the surges of the motor current were eliminated by the current reference drive of the BLDC motor. Thus, the cost and size of the solar panels were decreased in the power system of the satellite. In the CRM, the flywheel speed was decreased when disruptive impact occurred, but the speed of flywheel reached the reference speed in the determined time. Thanks to the CRM, the solar panel and satellite power system were protected from damage. The reference current was obtained by calculating the system losses. In the BLDC motor drive, the speed control was performed indirectly. However, the speed control of the BLDC motor can be satisfactorily achieved for the satellite power system. A trap-LC filter was designed to reduce the $\mathrm{d} v / \mathrm{d} t$ stress, current ripple, and THD which occurred due to the low inductance of the high-speed BLDC motor. The CRM complex system consisting of filter, current sensor, inverter and motor was used in the optimization of the PID parameters. The calculation of the PID parameters was performed by Ziegler-Nichols method and hybrid GA/PS algorithm. The current ripple of the BLDC motor was reduced by using the hybrid GA/PS algorithm.

As a result, the current surge of the high-speed BLDC motor was reduced by using the CRM in satellite power system applications. Thus, the solar power system was protected against undesirable current fluctuation of the motor. The hybrid GA was used to optimize the current controller parameters. In terms of the calculation of the PID parameters, the proposed optimization method was superior compared with the conventional method.

\section{REFERENCES}

[1] Lai, J., Song, Y., \& Du, X. (2018). Hierarchical coordinated control of flywheel energy storage matrix systems for wind 
farms. IEEE/ASME Transactions on Mechatronics, 23(1), 48-56. https://doi.org/10.1109/TMECH.2017.2654067

[2] Ghosh, S., \&Kamalasadan, S. (2017). An Energy FunctionBased Optimal Control Strategy for Output Stabilization of Integrated DFIG-Flywheel Energy Storage System. IEEE Transactions on Smart Grid, 8(4), 1922-1931. https://doi.org/10.1109/TSG.2015.2510866

[3] Li, W., Fang, J., Li H., \& Tang J. (2016). Position sensorless control without phase shifter for high-speed bldc motors with low inductance and nonideal back emf. IEEE Transactions on Power Electronics, 31(2), 1354-1366. https://doi.org/10.1109/TPEL.2015.2413593

[4] Itani, K., Bernardinis, A. D., Khatir, Z., \& Jammal, A. (2017) Comparative analysis of two hybrid energy storage systems used in a two front wheel driven electric vehicle during extreme start-up and regenerative braking operations. Energy Conversion and Management, 144, 69-87. https://doi.org/10.1016/j.enconman.2017.04.036

[5] Aydın, K., \& Aydemir, M. T. (2013). A control algorithm for a simple flywheel energy storage system to be used in space applications. Turkish Journal of Electrical Engineering \& Computer Sciences, 21(5), 1328-1339. https://doi.org/10.3906/elk-1111-65

[6] Aydın, K.\& Aydemir, M. T.(2016). Sizing design and implementation of a flywheel energy storage system for space applications. Turkish Journal of Electrical Engineering \& Computer Sciences, 24, 793-806. https://doi.org/10.3906/elk-1306-206

[7] Saxena, S. K., \& Saha, T. (2012). Ultra high speed operation of motor with enhanced motor dynamics for space limited applications. Aerospace Conference IEEE, Big Sky, 1-12. https://doi.org/10.1109/AERO.2012.6187243

[8] Feng, J., Liu, K., \& Wang, Q. (2018). Scheme based on buckconverter with three-phase h-bridge combinations for highspeed BLDC motors in aerospace applications. IET Electric Power Applications, 12(3), 405-414. https://doi.org/10.1049/iet-epa.2017.0615

[9] De S., Rajine M., Poosapati, S., Patel, C., \& Gopmakumar, K. (2012). Low-inductance axial flux BLDC motor drive for more electric aircraft. IET Power Electronics, 5(1), 124-133. https://doi.org/10.1049/iet-pel.2010.0329

[10] Song, X., Han, B., Zheng, S., \& Fang, J.(2018). Highprecision sensorless drive for high-speed BLDC motors based on the virtual third harmonic back-EMF. IEEE Transactions on Power Electronics, 33(2), 1528-1540. https://doi.org/10.1109/TPEL.2017.2688478

[11] Çelikel, R., Özdemir, M., \& Aydoğmuş, Ö. (2017). Reducing mechanical resonance time of a flywheel energy storage system by using a current control algorithm for satellites. Gazi University Journal of Science, 30(4), 200-214.

[12] Wai, R. J., Lee, J. D., \& Chuang, K. L. (2010). Real-time PID control strategy for maglev transportation system via particle swarm optimization. IEEE Transactions on Industrial Electronics, 58(2), 629-646. https://doi.org/10.1109/TIE.2010.2046004

[13] Abhishek \& Ansari, Md. F. (2013). An improved genetic algorithm with variable probability and immune genetic algorithm. International Journal of Advanced Research in Computer Science and Software Engineering, 3(10), 870873

[14] Benedik, B., Duhovnik, J., Rihtarsic, J., \& Tavcar, J. (2017). Thermal model of through flow universal motor by means of lumped parameter network. Technical Gazette-Tehnički vjesnik, 24(2), 405-412. https://doi.org/10.17559/TV-20161115224752

[15] Vukobratović, M., Marić, P., \& Hederić, Ž. (2016). Voltage and power losses control using distributed generation and computational intelligence. Technical Gazette-Tehnički vjesnik, 23(4), 937-944.

https://doi.org/10.17559/TV-20130618144654
[16] Adhikari, N. P., Choubey, M., \& Singh, R. (2012). DC motor control using Ziegler Nichols and genetic algorithm technique. International Journal of Electrical, Electronics and Computer Engineering, 1(1), 33-36.

[17] Durgadevi, S. \& Umamaheswari, M. G. (2018). Analysis and design of single phase power factor correction with DC-DC sepic converter for fast dynamic response using genetic algorithm optimised PI controller. IET Circuits, Devices \& Systems, 12(2), 164-174. https://doi.org/10.1049/iet-cds.2017.0229

[18] Kenny, B. H. \& Santiago, W. (2004). Filtering and control of high speed motor current in a flywheel energy storage system. NASA/TM-213343. https://doi.org/10.2514/6.2004-5627

[19] Fang, J., Li, W., \& Li, H. (2014). Self-compensation of commutation angle based on dc-link current for high-speed brushless dc motors with low inductance. IEEE Transactions on Power Electronics, 29(1), 428-439. https://doi.org/10.1109/TPEL.2013.2254499

[20] Awadallah, M. A., Bayoumi, E. H. E., \& Soliman, H. M. (2009). Adaptive deadbeat controllers de drives using PSO and ANFIS techniques. Journal of Electrical Engineering, 60(1), 3-11.

[21] Todić, I., Miloš, M., \& Pavišić, M. (2013). Position and speed control of electromechanical actuator for aerospace applications. Technical Gazette-Tehnički vjesnik, 20(5), 853860.

[22] Ziegler, J. G. \& Nichols, N. B. (1942). Optimum settings for automatic controllers. Transaction of the ASME, 65, 759. 765.

[23] Srikanth, S. \& Chandra, G. R. (2012). Modeling and PID Control of the Brushless DC Motor with the help of Genetic Algorithm. IEEE - International Conference on Advances in Engineering, Science and Management / Nagapattinam, Tamil Nadu, 639-644.

[24] Neath, M. J., Swain, A. K., Madawala, U. K., \& Thrimawithana, D. J. (2014). An optimal PID controller for a bidirectional inductive power transfer system using multiobjective genetic algorithm. IEEE Transactions on Power Electronics, 29(3), 1523-1531. https://doi.org/10.1109/TPEL.2013.2262953

[25] Ali, M. O., Koh, S. P., \& Chong, K. H., Hamoodiand, A. S. (2011). Design a PID controller of BLDC motor by using hybrid genetic-immune. Modern Applied Science, 5(1), 7585. https://doi.org/10.5539/mas.v5n1p75

[26] Kanai, M. M., Nderu, J. N., \& Hinga, P. K. (2011). Adaptive pid dc motor speed controller with parameters optimized with hybrid optimization strategy. $2^{\text {nd }}$ International conference on Advances in Engineering and Technology, Kampala, Uganda, 121-127.

[27] Vaz, A. I. F. \& Vicente, L. N. (2007). A particle swarm pattern search method for bound constrained global optimization. J Glob Optim., 39(2), 197-219. https://doi.org/10.1007/s10898-007-9133-5

[28] Anandaraju, M. B., Puttaswamy, P. S., \& Rajpuro, J. S. (2011). Genetic algorithm: an approach to velocity control of an electric dc motor. International Journal of Computer Applications, 26(1), 37-43. https://doi.org/10.5120/30664191

\section{Contact information}

Reşat ÇELIKEL (Corresponding author)

Batman University

72100, Batman, Turkey

resat.celikel@gmail.com

Mehmet ÖZDEMIR

Fırat University

23119, Elazıg, Turkey

mozdemir@firat.edu.tr 